\title{
EFFECTS OF ACETYLCHOLINE AND ADRENALINE ON THE ATRIAL FIBRILLATION
}

\author{
Masayosi Goto AND Tadasi TAMAI* \\ Department of Physiology, School of Medicine \\ Kyushu University, Fukuoka, Japan
}

It is generally conceived that increased vagal tone or parasympathomimetic drugs can dispose to or actually induce auricular fibrillation under propitious circumstances (Dipalma \& Schults, 1950 ; Scherf, Schaffer \& BlumenFEld, 1953 ; Burn, Vaughan Williams \& Walker, 1955; Burn, 1960). Meanwhile, adrenaline or sympathetic stimulation is known to have no special effect although under unusual circumstances they act as potent fibrillatory factors (Dipalma \& Schults, 1950; GoOdFord, 1958; VAughan Williams, 1963). However, the causes of action of these parasympathetic or sympathetic factors on the atrial fibrillation have not been elucidated as far as the cellular level is concerned.

In order to clarify these points, authors have performed a series of experiments with microelectrodes on the effects of acetylcholine and adrenaline on the aconitine-induced fibrillation, and found that the effects are considerably different depending on the sites not only in the atrium but also in the ventricle (Goto, Kawauchi \& Senoo, 1965 in preparation). Present communication is exclusively confined to the observation on the sinoatrial node and the ordinary right atrial fibers.

\section{METHOD}

Atria were excised from young rabbits and the right atrium was fixed in a lucite chamber irrigated with oxygenated Tyrode's solution at a constant flow and constant temperature $\left(30-35^{\circ} \mathrm{C}\right)$.

For inducing the fibrillation a $0.05 \%$ solution of aconitine (Merck; aconitinum purum cryst. ex Aconito Napello) was instilled in the chamber after stopping the flow of perfusate to make the final concentration to be $0.8 \sim 1.5 \times 10^{-6} \mathrm{~g} / \mathrm{ml}$. After all activities ceased (usually in a few minutes), reopening the flow caused a gradual appearance of fibrillation (GoTO, TAMAI and YANAGA, 1963). Thus induced fibrillation usually continued for hours, and hence during this period, acetylcholine and adrenaline in final concentration of $10^{-7} \sim 10^{-4} \mathrm{~g} / \mathrm{ml}$ were applied by instilling them in the bubbling chamber after stopping the flow.

Received for publication October 29, 1964

$*$ 後藤昌義, 王井 忠 
Transmembrane potentials before and after these procedures were traced on single cells of the right atrium and pace-maker region with the aid of flexibly mounted microelectrodes. The potential changes were amplified and the features were recorded by conventional techniques such as a long recording camera and an ink-writing oscillograph.

\section{RESULTS}

1. Effects of acetylcholine (ACh) on the sinoatrial node during aconitine-induced arrhythmia. Even when proper atrial muscle showed a typical pattern of aconitine-induced fibrillation, the sinoatrial node was not necessarily fibrillating. This region appeared actually to be an area of local block, for it often was out of phase with the electrical activity of the surrounding atrial muscle. FIG. $1 \mathrm{~A}$ shows an activity of the latent pace-maker cell in the sinoatrial node under these conditions. Either abortive or large spike followed after each peak of latent pace-maker potential with a notch, suggesting an existence of local block. After exposure to ACh $\left(6 \times 10^{-5}\right)$, hyperpolarization of the membrane, transient increase in spike amplitude and depression of the pace-maker potential were produced (FIG. 1A, B). In consequence, the activity changed gradually into a type of follower cell without showing diastolic depolarization, then it decreased in spike frequency and amplitude, and finally ceased (FIG. 1C).

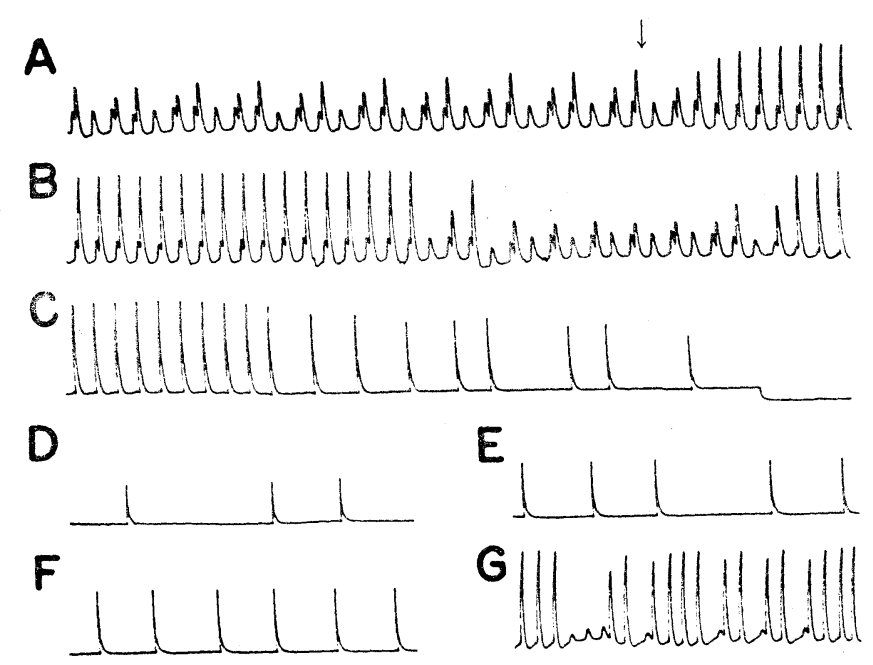

FIG. 1. Effects of acetylcholine (ACh) on intracellular potentials of the sinoatrial node during aconitine-induced arrhythmia. A) Control before exposure to $\left.\mathrm{ACh}\left(6 \times 10^{-5}\right), \mathrm{B}\right)$ immediately after, and C) $13 \mathrm{sec}$ after the exposure. D) $5 \mathrm{~min}$, E) $15 \mathrm{~min}$, F) $15.5 \mathrm{~min}$ and G) $20 \mathrm{~min}$ after removal of ACh by continuous flow. Note dramatic disappearance of diastolic depolarization. For further description see text. Time scale: $1 \mathrm{sec}$. 
The cause of hyperpolarization probably was an increase in potassium permeability of the membrane due to $\mathrm{ACh}$, but that of depression and disappearance of pace-maker potential was not clear whether it was due to the increase in potassium permeability or pace-maker shift.

After reintroduction of normal Tyrode solution, gradual recovery from the actions of ACh occurred generally in order of first an appearance of small spike in low frequency, then an increase in spike amplitude and rhythm, and finally an appearance of pace-maker potential followed by abortive or full spike (FIG. $1 D, E, F, G)$. Thus, the effects of $\mathrm{ACh}$ on the sinoatrial node during the atrial fibrillation were found reversible and fundamentally the same as its well known actions on the normal node.

2. Actions of ACh on the proper atrial muscle during the fibrillation. Atrial fibrillation due to aconitine used to appear more typically in the proper atrial muscle than in the sinoatrial node. Application of ACh to the atrium under this condition usually resulted in a dramatic recovery from the fibrillation. Typical records obtained from a single fiber in the epicardial side of atrial roof are shown in FIG. 2. After exposure to $\mathrm{ACh}\left(10^{-5}\right)$ at the time between

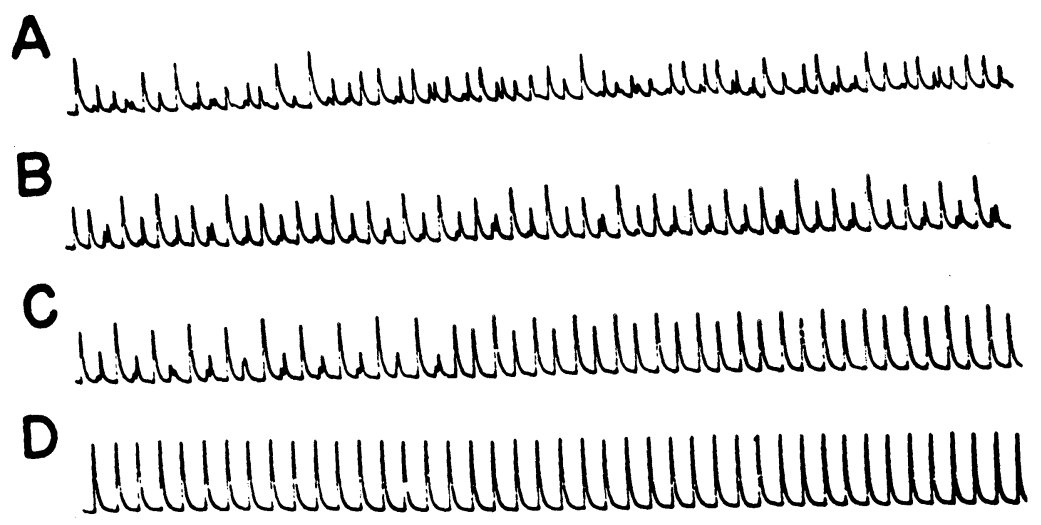

FIG. 2. Recovery of aconitine-induced atrial fibrillation by ACh. Records were obtained from a single fiber on epicardial side of the right atrial roof. ACh $\left(10^{-5}\right)$ was applied between the records $A$ ) and B). C) $35 \mathrm{sec}$, and D) $60 \mathrm{sec}$ after the application. Time scale: $1 \mathrm{sec}$.

$A$ and $B$, irregularity in rhythm and amplitude of the action potential (AP) rapidly diminished and disappeared, recovering a regular and full-sized AP in a minute. FIG. 3 illustrates similar records obtained simultaneously from two different fibers on the epicardial side of the atrium. The upper trace from the appendage shows a regular pattern of discharges while the lower one from 


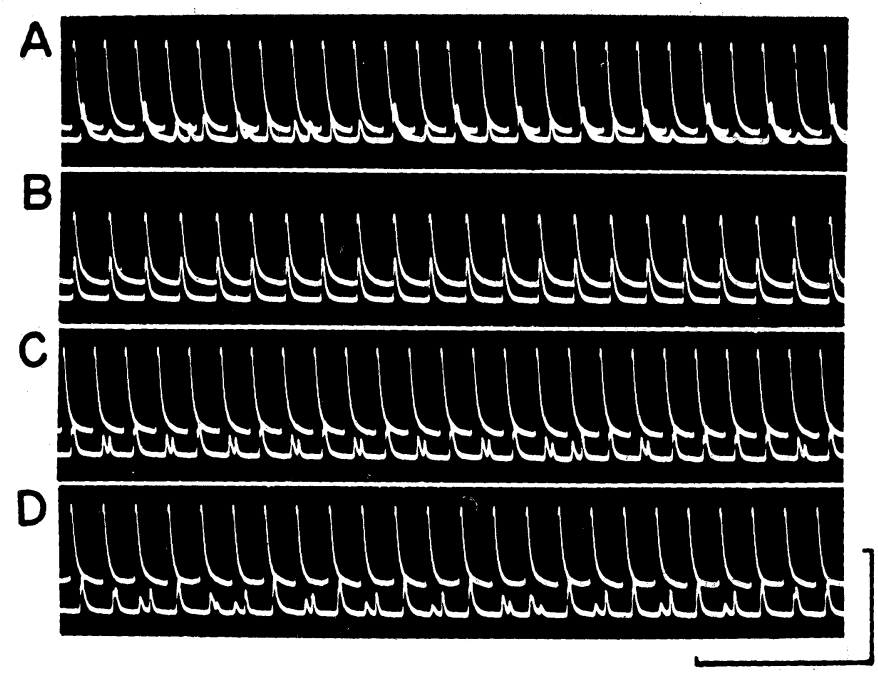

FIG. 3. Effects of ACh on the atrial fibers. The intracellular potentials were recorded simultaneously from two fibers on the epicardial side, one of the appendage (upper trace), and the other of the atrial roof (lower trace). A) Control. B) 2 min after exposure to $\mathrm{ACh}\left(10^{-5}\right)$. C) $10 \mathrm{~min}$, and D) $15 \mathrm{~min}$ after reintroduction of normal solution. Calibrations are $500 \mathrm{msec}$ and $10 \mathrm{mV}$.

atrial roof displays an irregular fibrillatory activity (A). When $\mathrm{ACh}\left(10^{-5}\right)$ was administered, no remarkable change was induced in the upper trace except a slight reduction of the AP rhythm, but in the lower trace irregular small potentials disappeared educing a regular rhythm which was well synchronized with that of upper trace (B). However, reopening of the flow of normal Tyrode solution caused a return to the former state of fibrillation in about ten minutes.

Effects of ACh in a higher concentration $\left(3 \times 10^{-4}\right)$ are presented in FIG. 4, the records of which were obtained simultaneously from two different fibers of the epicardial roof. The irregular and nonsynchronized discharges of two fibers (A) were changed into a regular and synchronized ones by $\mathrm{ACh}(\mathrm{B}, \mathrm{C})$. Conspicuous shortening of AP duration was also observable notwithstanding the acceleration and deceleration in rhythm of the discharge. Cause of the transient acceleration of rhythm was not clear, although it was presumed to be an irritant nonspecific action of high concentration of the drug. Anyhow, it must be noted that even this high concentration of $\mathrm{ACh}$ did not cease the spontaneous discharge, which was the case of sinoatrial node. Since in the atrium $\mathrm{ACh}$ did not affect the resting membrane potential markedly, some atrial fiber relatively resistive to $\mathrm{ACh}$ might have been activated as a pacemaker by the remaining action of aconitine. 


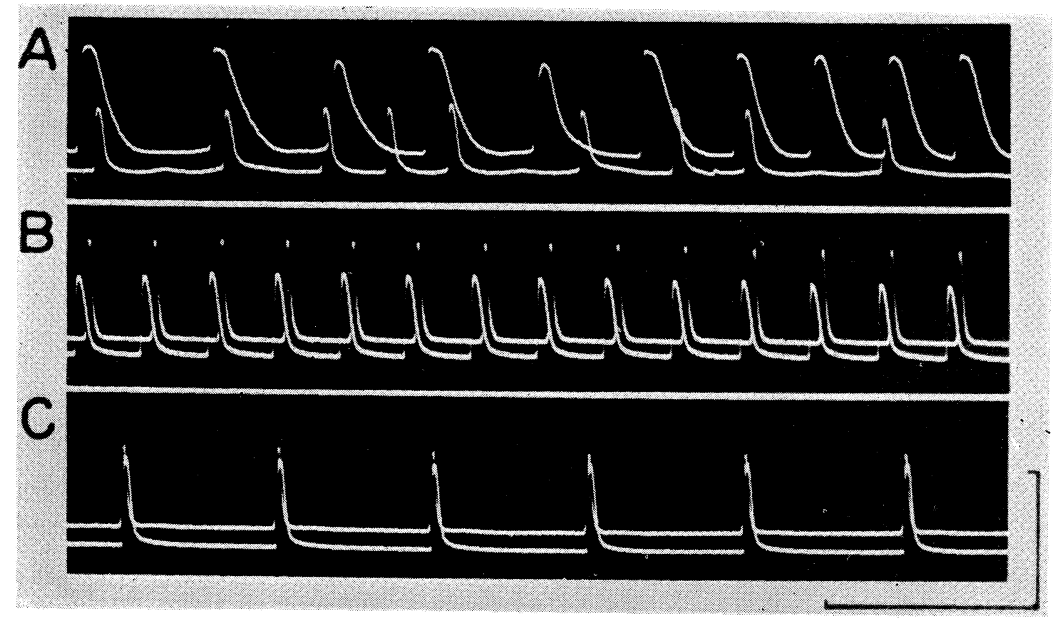

FIG. 4. Recovery of aconitine-induced atrial fibrillation by a high concentration of ACh. Records were obtained from two fibers on epicardial side of the atrial roof. A) Control, B) immediately after, and C) 2 min after application of $\mathrm{ACh}\left(3 \times 10^{-4}\right)$. Note an acceleration of AP rhythm by $\mathrm{ACh}$ in B. Calibrations are $500 \mathrm{msec}$ and $100 \mathrm{mV}$.

3. Atropine on the aconitine-induced fibrillation. A cholinergic blockade, atropine is generally known as an antifibrillator. However, since ACh was found to show a marked inhibitory action on the aconitine-induced fibrillation in our experiment, it will be rather expected of atropine some promotive action on the fibrillation. Whether it is the case or not will be a problem to be determined.

FIG. 5 illustrates an action of atropine on the transmembrane potentials of the atrial roof during the fibrillation. In $\mathrm{A}$ of the figure, alternate appearance of small and large AP's is observable with some irregularity that may

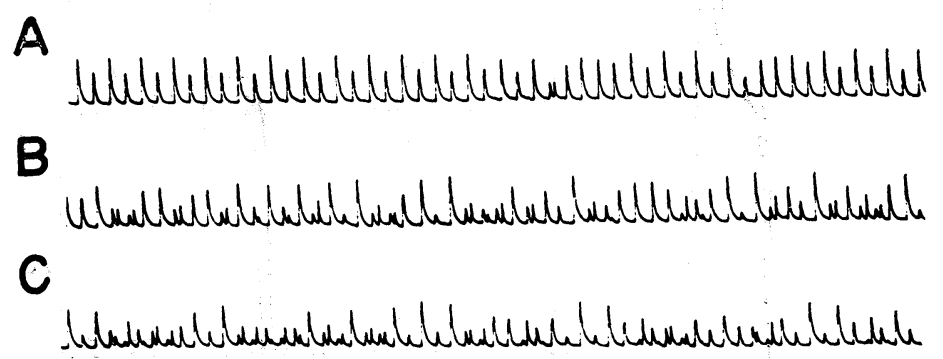

FIG. 5. Acceleration of aconitine-induced fibrillation by atropine. Records were obtained from a single fiber on epicardial side of the right atrial roof. A) Control, B) $1 \mathrm{~min}$, and C) 2 min after exposure to atropine $\left(10^{-7}\right)$. Time scale: $1 \mathrm{sec}$. 
be called an activity of sub-fibrillatory stage. When atropine of $10^{-7}$ in final concentration was added, the irregularity in AP amplitude and rhythm was enhanced (B) accompanying a slight depolarization of the membrane. Two minutes later, the tendency was further strengthened to show a typical pattern of fibrillation (C). Fig. 6 illustrates further an antagonistic action of atropine and $\mathrm{ACh}$ on the fibrillation. Upper traces of the records were obtained from a single fiber of the appendage, and lower traces from that of the atrial roof both on the epicardial side. The former shows a regular pattern of discharge throughout all records from $\mathrm{A}$ to $\mathrm{D}$ despite the application of atropine $\left(10^{-7}\right)$ in $\mathrm{B}$ and further addition of $\mathrm{ACh}\left(10^{-5}\right)$ in $\mathrm{D}$. However, the frequency of discharge was slightly increased by atropine and decreased by

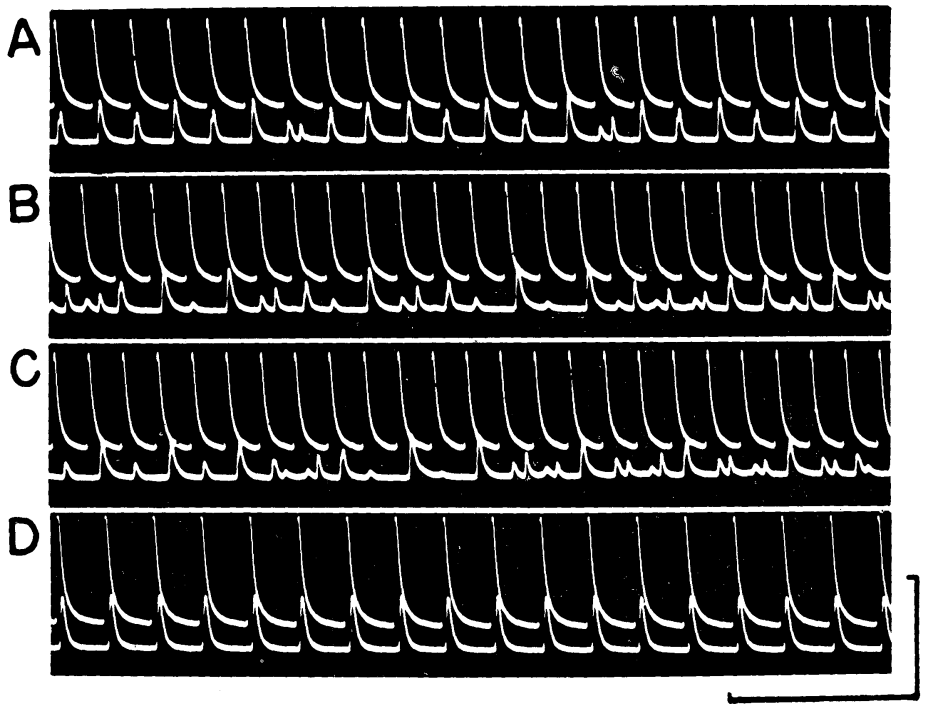

FIG. 6. Antagonistic effects of atropine and ACh on the atrial fibrillation. Simultaneous records of the transmembrane potentials were performed on two fibers, one of the appendage (upper record) and the other of the atrial roof (lower record) both from epicardial side. A) Control, B) $1.5 \mathrm{~min}$, C) $3 \mathrm{~min}$ after atropine $\left(10^{-7}\right)$. D) $1 \mathrm{~min}$ after $\mathrm{ACh}\left(10^{-5}\right)$. Calibrations are $500 \mathrm{msec}$ and $100 \mathrm{mV}$.

$\mathrm{ACh}$ as expected. On the other hand, the latter fiber in which irregular activity already existed (A), the irregularity was enhanced by the application of atropine inducing the more typical pattern of fibrillation $(B, C)$. When $A C h$ in the high concentration was added at this stage, the irregularity in rhythm and spike amplitude disappeared in a minute and a rhythmical discharge well synchronized with that of the upper trace was educed. After washing with normal Tyrode solution, atropine again acted in the similar way as in the first case. Thus, by repeating $\mathrm{ACh}$ and atropine infusions alternately, it was 
possible to start or stop the fibrillation several times. Therefore, so far as the aconitine-induced fibrillation of the rabbit right atrium is concerned, it will be now clear that atropine acts as an accelerator of the fibrillation antagonizing to the inhibitory action of ACh.

4. Effects of adrenaline on the aconitine-induced fibrillation. Clinical evidences are not so clear with respect to the effects of adrenaline or sympathetic stimulation on cardiac fibrillation. Furthermore, since the receptor sites of adrenaline and ACh were known different each other, it can not be expected a simple antagonistic action on fibrillation between them.

FIG. 7 represents the effects of adrenaline on the sinoatrial node (upper trace) and on the atrial roof (lower trace) under the remnant action of aconitine. In control record $\mathrm{A}$, both fibers of sinoatrial node and atrial roof discharge in a quite regular rhythm with fairly constant delay in the latter, but as seen in record B, they occasionally show some irregularity in rhythm or double spikes probably due to the action of aconitine. After administration of adrenaline of $10^{-6}$ in final concentration, the irregularity and the appearance of double spikes were intensified as shown in FIG.'s C, D and E. Although the

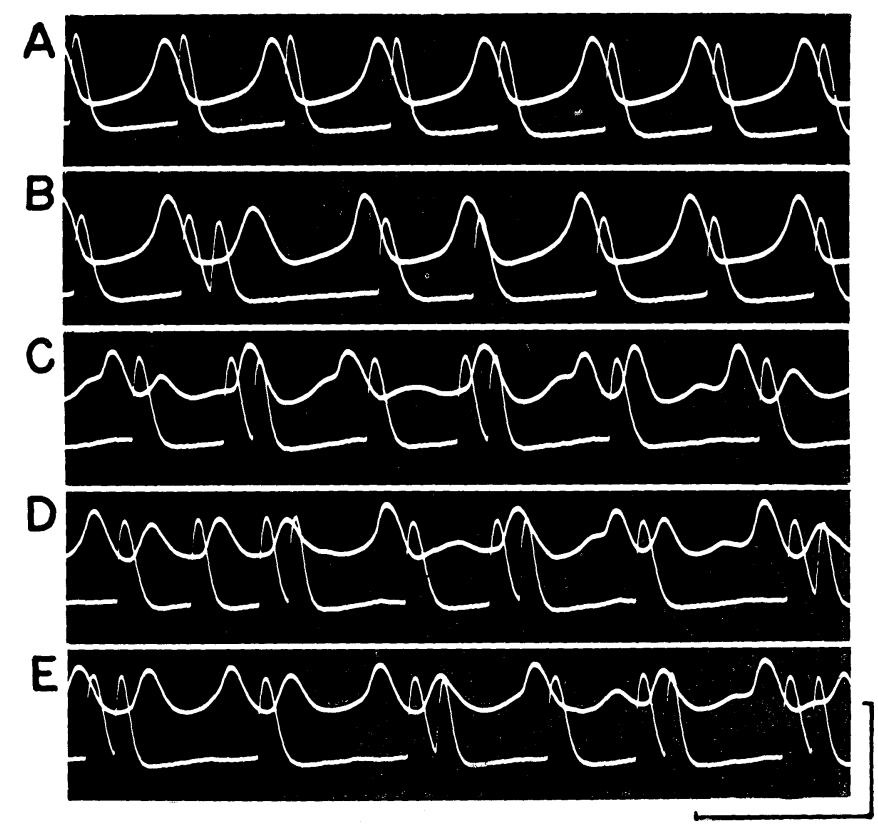

Fig. 7. Effects of adrenaline on the sinoatrial node and ordinary atrial fibers. Simultaneous records from two fibers on epicardial side, one of the sinoatrial node (upper trace) and the other of the atrial roof (lower trace). A) and B) Controls. C), D) and F) Records obtained in five minutes after application of adrenaline $\left(10^{-6}\right)$. Calibrations are $500 \mathrm{msec}$ and $100 \mathrm{mV}$. 
mean frequency of discharge was increased by the action of adrenaline, increase in gradient of the diastolic slow depolarization was not so clear because of the irregularity. However, it must be noted that new rhythmic small potential different in frequency was recorded simultaneously with the original pacemaker potential from a single fiber of the sinoatrial node. The small rhythmic potential might be an electrotonic spread of some ectopic pace-maker potential or that of AP generated by the ectopic pace-maker. Therefore, the principal cause of irregularity might be presumed to be the appearance of the ectopic pace-maker. Anyhow, the rhythmic potential gradually grow in size and appeared intermingled with the original pace-maker potential, at the same time the latter changed into latent pace-maker potential, being accompanied with a notch in the upstroke of AP. Thus, they will prove a cohabitation of two pace-makers or an occurrence of pace-maker shift both of which were also frequently observed under the microscope.

FIG. 8 shows the similar data obtained in the same series of experiment, but in another trial of adrenaline. More typical fibrillation was produced in a fiber of the sinoatrial node, probably because of the manifold appearance of

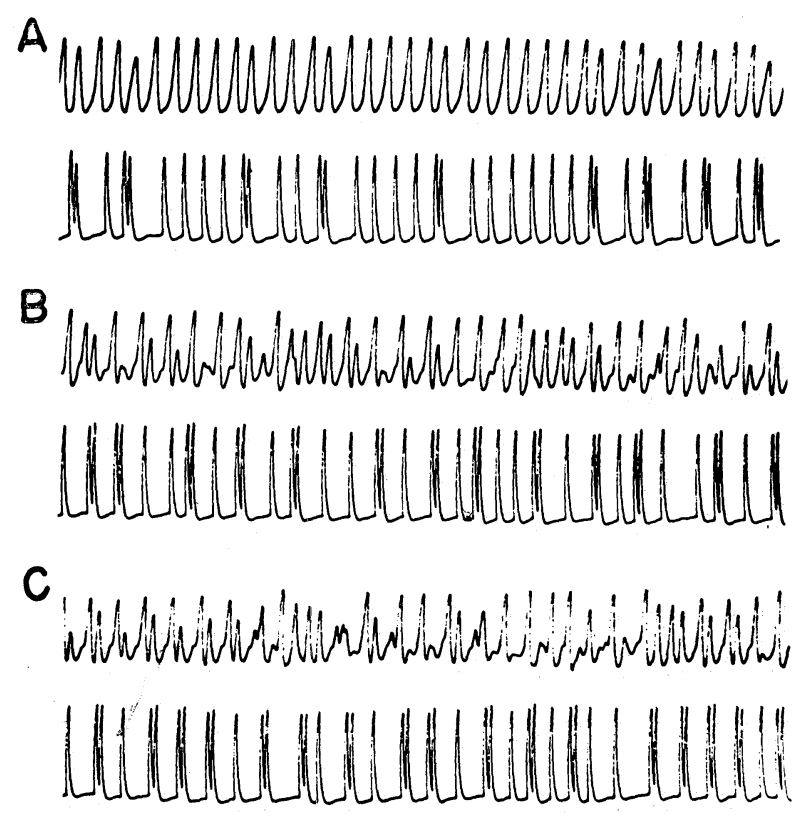

FIG. 8. The similar data as in FIG. 7 obtained from the same series of experiment. A) Control, B) $1 \mathrm{~min}$ and C) $2.5 \mathrm{~min}$ after exposure to adrenaline $\left(10^{-6}\right)$. Fibrillatory activity was produced more typically in a fiber of the sinoatrial node (upper trace) than in that of the atrial roof (lower trace). 
pace-makers. On the other hand in a fiber of the atrial roof, effects of adrenaline is not impressive in this case but an increase in mean frequency of discharge together with in number of double spikes and consequent shortening of AP-duration were observable.

\section{DISCUSSION}

1) Dual actions of ACh on the atrial fibrillation. ACh is generally known as a drug which predisposes to atrial fibrillation by reducing AP-duration and refractory period of the atrium and by increasing the rate of rise of $\mathrm{AP}$ and the conduction velocity (Dipalma \& Schults, 1950; Hoffman \& Suckling, 1953 ; Trautwein \& DudeL, 1958b). Actually, atrial fibrillation has been produced in the dog heart-lung preparation by combining electrical stimulation at a high rate during the infusion of ACh (BURN, VAUGHAN Williams \& WALKER, 1955; BURN, 1960). Even in the isolated rabbit atria, the fibrillation has been produced by brief stimulation in the presence of $\mathrm{ACh}$ and a low concentration of potassium (HOLLAND \& BURN, 1957).

On the other hand, in our experiment on the aconitine-induced fibrillation, ACh showed an inhibitory action on the irregular activity of the sinoatrial node, producing an increase in the resting potential, a decrease in the slope of diastolic depolarization and a consequent decrease in the pace-maker rhythm. These actions of $\mathrm{ACh}$ are quite similar to the effects of the vagal stimulation and $\mathrm{ACh}$ on the normal sinoatial node in many respects (WEST, 1955 ; Castillo \& Katz, 1955 ; Hutter \& Trautwein, 1956 ; West, Falk \& Cervoni, 1956; Trautwein \& Dudel, 1958a). Particularly in the proper atrial muscle, ACh was found to inhibit dramatically the fibrillation and to restore well synchronized AP's of equal magnitude, after depressing all irregular potentials.

How to understand the contradictory effects of ACh between these two kinds of fibrillation induced one by aconitine and the other by $\mathrm{ACh}$ plus electrical stimulation, would be an important problem. Some conflict might stem first from the dubious assumption that aconitine-induced and $\mathrm{ACh}$-induced arrhythmias are identical. Kennamer, Miles \& Prinzmetal (1957) believed that the fibrillation resulting from electrical stimulation was similar to the aconitine-induced fibrillation in that a rapidly discharging focus caused the arrhythmias, while Kimura, Kato et al. (1954) and Kato, SAto et al. (1956) concluded that they were different. In our opinion, they are identical in the pattern of fibrillation but considerably different in the cause of appearance or maintenance of the arrhythmia. In our preceding paper (GoTO, TAMAI \& YANAGA, 1963), it was pointed out as causes of the aconitine-induced fibrillation, 1) acceleration of pace-maker rhythm and consequent flutter, 2) formation of one or more ectopic foci, and 3) appearance of local block due to the 
accelerated rhythm or extrasystoles. On the other hand, in the ACh-induced fibrillation, a short period of high frequency stimulation was necessary as well as an infusion of ACh. Accordingly, the main cause of the fibrillation will be 1) electrical stimulation in high frequency and 2) shortening of AP-duration and refractory period due to ACh, as pointed out by BURN (1960).

Thus, in our case of aconitine fibrillation, acceleration of 'spontaneous' pace-maker rhythm plays a key role in educing fibrillation, while in the electrically induced one, forced 'driving' by the electrical stimulation and consequent shortening of refractory period act the part. When they are the cases, ACh would be expected to inhibit the aconitine-induced fibrillation by depressing the pace-maker activity as we have observed, but contrarily it would act to promote the electrically induced one by causing further shortening of the refractory period. In other words, ACh has dual parts of effects on fibrillation, acceleration by shortening the refractory period and deceleration by inhibiting the pace-maker rhythm, and which part of them appears in dominance seems to depend on the kinds of fibrillation and on the condition and part of the heart under investigation (Goto, Kawauchi \& Senoo, 1965 in preparation).

2) Dual actions of adrenaline on the fibrillation. Effects of adrenaline or sympathetic stimulation on cardiac fibrillation have not been fully clarified. Although adrenaline per se is not a fibrillatory drug (WEGRIA \& NICKERSON, 1942 ; Dipalma \& SchulTs, 1950) and rather acts as antifibrillatory in normal heart (BURN, 1960), it becomes a potent fibrillatory drug under unusual circumstances such as thyrotoxicosis, hypoxia and various kinds of anesthesia (see LoRber, 1958; Hoffman \& Kavaler, 1961; Milnor, 1962). Especially in the ventricle adrenaline tends to induce a fibrillation by stimulating the $\beta$-receptor (VAUGHaN Williams, 1963).

In our case of the rabbit sinoatrial node under the effect of aconitine, adrenaline caused an acceleration of the pace-maker rhythm, frequent shift in pace-maker site, and/or production of one or more ectopic pace-makers, and in consequence an enhancement of fibrillation. Effect of adrenaline on the proper atrial muscle was not impressive, but irregularity in AP rhythm and height was slightly strengthened, educing the more frequent appearance of double spikes. Thus, adrenaline tended to promote the aconitine-induced fibrillation, and the results coincided well with the facts known on the atrium under the various abnormal conditions stated above. The reason will be that, when an acceleration of pace-maker rhythm and some local blocks which dispose an appearance of ectopic foci exist, adrenaline may act further to promote these factors and hence the fibrillation.

On the other hand, BURN, GunNing \& WALKER (1957) demonstrated that, whereas fibrillation followed electrical stimulation during the infusion of $\mathrm{ACh}$, 
it did not follow the stimulation during the infusion of adrenaline and $\mathrm{ACh}$ together. Thus they and BURN (1960) were led to a conclusion that adrenaline, which usually lengthened the AP, was antifibrillatory in effect.

These conflicting observations of the effects of adrenaline on fibrillation might be explained also by its dual sites of action. If the acceleration of pace-maker rhythm and the consequent appearance of local block are dominant in effects, fibrillation will be produced, while if the lengthening of AP-duration and refractory period is dominating, fibrillation will be ceased. Which part of the actions has the predominance seems also to depend on the kinds of fibrillation, the condition and the portion of cardiac muscle as in the case of ACh (Goto, Kawauchi \& Senoo, 1965).

3) Presumed ionic backgrounds of fibrillation. KLEIN \& Holland (1960) and BRIGGS \& HollAND (1961) have obtained further evidence to support their thesis that fibrillation is initiated by increase in sodium flux above a critical value. The effect of quinidine on sodium and potassium flux are consistent with the hypothesis that it acts primarily by inhibiting sodium entry (KLEIN, Holland \& Tinsley, 1960). These results also accord well with those of SZEKERES \& VAUGHAN WILliAMS (1962) that many antifibrillatory drugs produced lengthening of the effective refractory period, decrease in rate of rise of AP and in conduction velocity, suggesting an inhibition of sodium entry. Thus, it seems now well established that acceleration of sodium entry plays a principal role in inducing cardiac fibrillation.

In connection with this, authors want further to point out the importance. of role of the pace-maker potential, appearance of which also depends on sodium entry (Dudel \& Trautwein, 1958; Trautwein \& Kassebaum, 1961 ; Engstfeld, Antoni \& Fleckenstein, 1961; Noble, 1962). In our case of the aconitine-induced fibrillation, in which the acceleration of pace-maker rhythm plays a fundamental role (GoTo, TAMAI \& YANAGA, 1963), it was clearly demonstrated that ACh inhibited the fibrillation by depressing the pace-maker activity while adrenaline enhanced the fibrillation by accelerating the rhythm. Ionic theory on the cardiac muscle (NoBLE, 1962) seems further to support this view not only by the theoretical calculation but also by the experimental facts in its background. When the constants determining the activation of sodium carriers are changed, the computed solutions show prominent pace-maker potentials. Dudel \& Trautwein (1958) and Trautwein \& Kassebaum (1961) presented further evidences relating the sodium conductance of the membrane to the generation of spontaneous heart beat, and clarified that pace-maker activity was produced or enhanced by conditions which increased the sodium conductance.

Thus, it might be concluded that the cause of the fibrillation in primary importance would be a facilitation of sodium conductance, resting or active, 
and hence an ideal antifibrillator must have some actions of inhibiting or antagonizing to this factor. Along this sort of consideration, confused and complicated factors such as the rate of rise, rate of fall, AP duration or refractory period, which have been discussed separately concerning cardiac fibrillation, might be consolidated into a simplified feature.

\section{SUMMARY}

1. Effects of acetylcholine and adrenaline on the aconitine-induced fibrillation were studied with microelectrodes on the right atrium isolated from young rabbits.

2. In the proper atrial muscle, acetylcholine $\left(10^{-5} \sim 10^{-4}\right)$ inhibited dramatically the fibrillation and restored well synchronized and rhythmical discharges of equal magnitude.

3. In the sinoatrial node, acetylcholine also showed an inhibitory action on the irregular activity, producing an increase in resting potential, a decrease in slope of diastolic depolarization and a consequent decrease in pace-maker rhythm.

4. Contrarily, atropine $\left(10^{-7}\right)$ was found to facilitate the aconitine-induced atrial fibrillation. Thus, by repeating acetylcholine and atropine infusions alternately, the fibrillation was possible to start or stop several times.

5. Adrenaline $\left(10^{-6}\right)$ promoted the aconitine-induced fibrillation, in concequence of an acceleration of pace-maker rhythm, frequent shift in pace-maker site and/or a production of two or more ectopic pace-makers. In the proper atrial muscle effect of adrenaline was not impressive, although it enhanced the rate of discharge and its irregularity.

6. Conflicting observations on effects of acetylcholine or adrenaline specially between the two kinds of fibrillation induced one by aconitine and the other by acetylcholine plus electrical stimulation were discussed, and dual sites of action of each drug were pointed out.

Finally, it was estimated that the cause of fibrillation in primary importance is a facilitation of sodium conductance which elicites an acceleration of the pace-maker potential.

\section{REFERENCES}

1) BRiggs, A.H. And Holland, W.C. (1961) Transmembrane fluxes in ventricular fibrillation. Amer. J. Physiol., 200 : 122-124.

2) Burn, J.H. (1960) The cause of fibrillation. British Med. J., $5183: 1379-1384$.

3) Burn, J.H., Gunning, A. J. And WAlker, J.M. (1957) Effects of noradrenaline and adrenaline on the atrial rhythm in the heart-lung preparation. J. Physiol., $137: 141-153$.

4) Burn, J.H,, Vaughan Williams, E. M. And Walker, J. M. (1955) The Effects of acetylcholine in the heart-lung preparation including the production of auricular 
fibrillation. J. Physiol., $128: 277-293$.

5) Castillo, J. Del. and Katz, B. (1955) Production of membrane potential changes in the frog's heart by inhibitory nerve impulses. Nature, $175: 1035$.

6) DiPalma, J.R. And Schults, J.E. (1950) Antifibrillatory drugs. Medicine, 29 : 123-168.

7) Dudel, J. und Trautwein, W. (1958) Der Mechanismus der automatischen rhythmischen Impulsbildung der Herzmuskelfaser. Pflïg. Arch., 267 : 553-565.

8) Engstfeld, G., Antoni, H. And Fleckenstein, A. (1961) Die Restitution der Erregungsfortleitung und Kontraktions Kraft des $\mathrm{K}^{+}$gelähmten Frosch- und Sägetiermyokards durch Adrenalin. Pflïg. Arch., 273 : 145-163.

9) Goodford, P. J. (1958) Metabolic factors and ventricular fibrillation. British J. Pharmacol. \& Chemotherapy. 13 : 144-150.

10) Goto, M., Kawauchi, Y. And Senoo, K. (1965) in preparation.

11) Goto, M., Tamai, T. And Yanaga, T. (1963) Studies on the appearance and termination of aconitine-induced fibrillation with microelectrodes. Jap. J. Physiol., 13: 196-207.

12) Hoffman, B.F. and Cranefield, P.F. (1960) Electrophysiology of the heart. McGraw-Hill, New York, Tronto and London.

13) Hoffman, B. F. and Kavaler, F. (1961) Heart. Ann. Rev. Physiol., 23: 327-356.

14) Hoffman, B.F. And Suckling, E. E. (1953) Cardiac cellular potentials : effect of vagal stimulation and acetylcholine. Amer. J. Physiol., 173: 312-320.

15) Holland, W.C. And Burn, J. H. (1957) Production of fibrillation in isolated atria of rabbit heart. Brit. Med. J., 1: 1031-1033.

16) Hutter, O.F. and Trautwein, W. (1956) Vagal and sympathetic effects on the pace-maker fibers in the sinus venosus of the heart. J. Gen. Physiol., 39 : 715-733.

17) KAto, K., SAto, M. et al. (1956) Clinical studies on the nature of the auricular flutter. Tôhoku J. Exptl. Med. $64:$ 377-387.

18) Kennamer, R., Miles, E. And Prinzmetal, M. (1957) Studis on Lewis' auricular flutter of post-electrical stimulatory origin. Clin. Sci., 16: 451-461.

19) Kimura, E. Kato, K. et al. (1954) Experimental studies on the mechanism of auricular flutter. Tôhoku J. Exptl. Med. 60 : 197-207.

20) Klein, R.L. And Holland, W.C. (1960) Transmembrane potentials and atrial fibrillation. Amer. J. Physiol., 199: 346-348.

21) Klein, R. L., Holland, W.C. And Tinsley, B. (1960) Quinidine and unidirectional cation fluxes in atria. Circulation Research, $8: 246-252$.

22) Lorber, V. (1958) Heart. Ann. Rev. Physiol., $20: 97-122$.

23) Milnor, W. R. (1962) Heart. Ann. Rev. Physiol., 24 : 169-198.

24) Noble, D. (1962) A modification of the Hodgkin-Huxley equations applicable to Purkinje fiber action and pace-maker potentials. J. Physiol., 160: 317-352.

25) Scherf, D., Schaffer, A. I. And Blumenfeld, S. (1953) Mechanism of flutter and fibrillation. Archiv Intern. Med., $91: 333-352$.

26) Szekeres, L. and Vaughan Williams, E.M. (1962) Antifibrillatory action. J. Physiol., $160:$ 470-482.

27) Trautwein, W. und Dudel, J. (1958a) Zum Mechanismus der Membranwirkung des Acetylcholin an der Herzmukelfaser. Pflüg. Arch., 266 : 324-334.

28) Trautwein, W. und Dudel, J. (1958b) Hemmende und erregende Wirkungen des Acetylcholin am Warmblüterherzen. Zur Frage der spontan Erregungsbildung. Pflïg. Arch., 266 : 653-664.

29) Trautwein, W. and Kassebaum D. (1961) On the mechanism of spontaneous impulse generation in the pace-maker of the heart. J. Gen. Physiol., 45:317-330.

30) Vaughan Williams, E. M. (1963) Fibrillation. Annotations. $66: 569-572$. 
31) Webb, J. L. and Hollander, P. B. (1956) The action of acetylcholine and epinephrine on the cellular membrane potentials and contractility of rat atrium. Circulation Research, 4 : 332-336.

32) Weidmann, S. (1957) Elektrophysiologie der Herzmuskelfaser. Hans Huber, Bern und Stuttgart.

33) West, T.C. (1955) Ultramicroelectrode recording from the cardiac pace-maker. J. Pharmacol. Exptl. Therap., 115: 283-290.

34) West, T.C., Falk, G. and Cervoni, P. (1956) Drug alteration of transmembrane potential in atrial pace-maker cells. J. Pharmacol. Exptl. Therap., 117 : 245-252.

35) Wegria, R. And Nickerson, N.D. (1942) The effect of papaverine, epinephrine and quinidine on the fibrillation threshold of mammalian ventricles. J. Pharm. \& Exper. Therap., $75: 50-57$. 